\title{
Development of farming in Russia aspiring to solve rural environmental issues
}

\author{
Igor Aleksandrov ${ }^{1, *}$, Marina Fedorova ${ }^{2}$, and Aleksey Parshukov ${ }^{1}$ \\ ${ }^{1}$ Peter the Great St.Petersburg Polytechnic University (SPbPU), Polytechnicheskaya 29, 195251, \\ St. Petersburg, Russia \\ ${ }^{2}$ Petrozavodsk State University, Lenina 33, 185910, Petrozavodsk, Russia
}

\begin{abstract}
The objective of the article is to analyze the share and the amount of farm households in the regions of the North Western Federal District of Russia. The period chosen for the analysis makes from 2005 to 2019, excluding to year 2020 due to particular circumstances connected with COVID-19. We assume, that development of farm households, in case it takes place, should be supplemented by the creating different kinds of non-importables connected with agricultural industry. Those nonimportables can be promoted and sold with the help of Internet and to diversify the main product farms, so to raise their incomes. All those suggestions are the main goal to contribute in rural poverty eradication which leads to outmigration, dying of the countryside and serios ecological problems. Those ecological problems cannot be solved by poor people, but we assume that farmers getting profit from their territory are interested in preserving the environment, and we find the confirmation of this statement on our field research.
\end{abstract}

\section{Introduction}

At the present time the countryside of the Russian Federation faces threatens to disappear due to lack of infrastructure, low level of life and low salaries. The outmigration just worsens the lack of infrastructure problems due to the policy of optimization. We see that the bottom up development initialized by locals could be more appropriate and viable option for Russian villages. Taking into account the development of Internet and possibilities it offers to whose who is ready to start their entrepreneurship activity, we argue that the process of dying Russian villages can be stopped to some extent.

Another problem of vast territories of the Russian Federation, which population density is very low, as a rule, is ecological problem. Pure rivers, lakes and land are being devastated and polluted due to lack of treatment facilities. The authorities do not invest in treatment facilities of small or tiny villages. That is why nature degrades because of irresponsible agricultural industries, tourists, dumping of big cities' rubbish for money. That is another point we see the importance of small farming development in the countryside aspiring its sustainability.

\footnotetext{
* Corresponding author: a7830298@gmail.com
} 
The objective of this paper is to analyze the development of farm households in regions of the North Western Federal District during the period from 2005 to 2019. The period of 2020 is not analyzed due to circumstances inflicted by COVID-19. The data from the Federal Service of Tax were gathered and processed to examine the amount and the share of farm households of districts of the North Western Federal District. With the help of our findings we confirm the needed measures to be undertaken to continue the development of farming in the countryside of the North western Federal District. The literature review included the analysis of Russian and foreign researches concerning sustainable development of the countryside, notably, rural development in digital era.

\section{Literature Review}

As to the environment, the important issue is that as T. A. Masron and Y. Subramaniam (3) assume that there is the "linear relation between environmental degradation and income" in developing countries. The authors also estimates the rate of poverty which is statistically significant to make damage to the environment. That is why poverty reduction is needed to be the main point to develop countryside and to prevent its natural resources degradation.

Mironova N. A. and al. (1) argue that farm households make a significant part of the Russian GDP. But we also underline the socio-territorial importance of farm households' development mentioned by the authors, such as new job places, preserving the countryside and rural culture and integrating active rural community to the entrepreneurship. Marinichenko T.E. (2) affirms that up to $90 \%$ of agricultural products needed can be produced by Russian farmers themselves. L. Christiaensen and al. (4) found that the development agriculture works better and more efficiently for poverty eradication. Talking about bottom-up development and preserving cultural authenticity we agree with Ray C. (5) and argue that not only agricultural products, but some sorts of non-importables, as it is proposed by Van der Ploeg et al. (5) connected with agriculture and faming can be a product at the era of digitalization, as Bahaman A.S. et al. (7), and Strebkov D.O et al. (8) assume. That is why it is very important is to develop long food chains, and consequently, for municipal and regional economy.

We see that partial bottom-up development of rural communities could help to solve the environmental and poverty problems. The more entrepreneurs are in the countryside, the more taxes are paid into the budget of the community. Moreover, it improves the civil activity of rural people which strongly important to save rural territory and its culture with the lack of resources.

Popular entrepreneurial activity nowadays is "lifestyle entrepreneurship » when individuals earn money doing sorts of activity they prefer most of all. Cunha C. et al. (4) consider such type of entrepreneurship successful

According to Fedorova M. Yu. and Alexandrov I.N. (5) with the development of the Internet farm households can facilitate their output with the help of social media and networking tools. As Kaila H. and Tarp F. (6) point out the Internet access makes the value of agricultural output from 6 to $7 \%$ higher. Talking about networking and social networks, A. Abdul-Rahaman, A. Abdulai (7) argue that farmers benefit from social networks including higher prices and market performance outcomes. Nevertheless, the researches talk about rice, we see that the same pattern works for other farm products. A. AbdulRahaman, A. Abdulai (8) also point out the higher efficiency of farmers belonging to different farmers' groups.

But the negative point, as it is found in the researches of Fedorova M. Yu. and Aleksandrov I.N. (14) about agricultural and other sorts of entrepreneurship in the countryside with the help of Internet is that locals do not aware of tools and ways to earn money in such a way. 
Regarding the issues of the environment and farming development, J. R. Anderson (9)points out the need in investment into the knowledge of farmers to prevent the environment degradation.

We can look at the data of the farm households for the period from 2005 to 2019. The period of 2020 was excluded because of special situation cause by COVID-19. The data was taken from the official site of the Federal Tax Service of the Russian Federation. As far as our research covers extended period of time we argue that it is also useful to analyze the farm household surplus in Saint-Petersburg also. And to compare it with other regions the North-Western Federal District.

\section{Methodology}

The North-Western Federal District was chosen to make the analysis of the development of farm households. To gather the data the statistics from the Federal Tax Service of Russia was taken for the period from 2005 to 2019 . The year 2020 was excluded from the analysis due to special circumstances of this year brought by COVID-19. That is why we see that the situation during the whole year of 2020 should be revised along. For the analysis, all the districts of the North-Western Federal District were taken, including the main city and the biggest city of the area, Saint-Petersburg. Nevertheless this city shows another type of area and relationships among individuals in the community, it stays interesting to look at the development and the rate of farming households of this city. Firstly, we revised absolute grow of farm households in the districts of the North-Western Federal District. Secondly, we revised the share farm households make in its own region. The share was analyzed in comparison to the whole population of a district and in comparison to rural population of district.

\section{Research}

According to the Figure 1, we see that the amount of farm households is the smallest in Murmanskaya Oblast. It grows just a little during the whole period but not even shifts over one hundred. Almost always, the highest amount of farm households stays in Leningradskaya Oblast. Only in 2017 year its amount is lesser than in the amount of farm household in Saint-Petersburg, but it is explained by the sharp rise which is consequent then the same sharp step-down and takes it middle position as it used to be. The second leader according to the amount of farm households registered on its territory during the period from 2005 to 2019 is Novgorodskaya Oblast.

We also see that from 2005 to 2006 Leningradskaya Oblast, Nogorodskaya, Oblast, Kaliningradskaya Oblast, Arkchangelskaya Oblast, Vologodskaya Oblast, Pskovskaya Oblast and Musrmanskaya Oblast showed the decrease in the amount of farm households. Mostly, the deacrease was sharp, excluding only Arkchangelskaya Oblast and Murmanskaya Oblast. As to the last one, this region does not show nor sharp rises neither sharp decreases during the whole period, so we can tell that it is quiet stable. Moreover, the farming is not considered to be the most perspective for the economy of Murmanskay Oblast so we can see that its amount rises just a little bit.

Another period of rise is from 2006 to 2010 which is quite sharp almost for all regions. The fastest grow are shown for the period from 2009 to 2010 by Psovskaya Oblast, Komi Republic and sNovgorodskaya Oblast. It should be mentioned that the preceding period in those regions is more steadier. At the same time we see that other regions showing that grow for the period from 2006 to 2010 stay steady for the whole this period. Another period is the period of decrease which is longing from three to four years depending on a region. 
After 2013 we see the rise once again but it is quite. For example, after the period of decrease from 2010 to 2014 the steady grow is shown by the Republic of Karelia. The amount of farm households is the smallest and nevertheless the grow is slow but steady.

The reverse situation we see in Kaliningradskaya Oblast where the amount of farm households has been rising for the whole period but from 2017 it has been decreasing.

We can see also the decrease of farm households forecasted by Piterskaya L.Yu. et al. (3) with the help of extrapolation analysis made for the all Russian farmers. The authors argued that the decrease will be in the amount of households' population but it will be followed by the rise of stock.

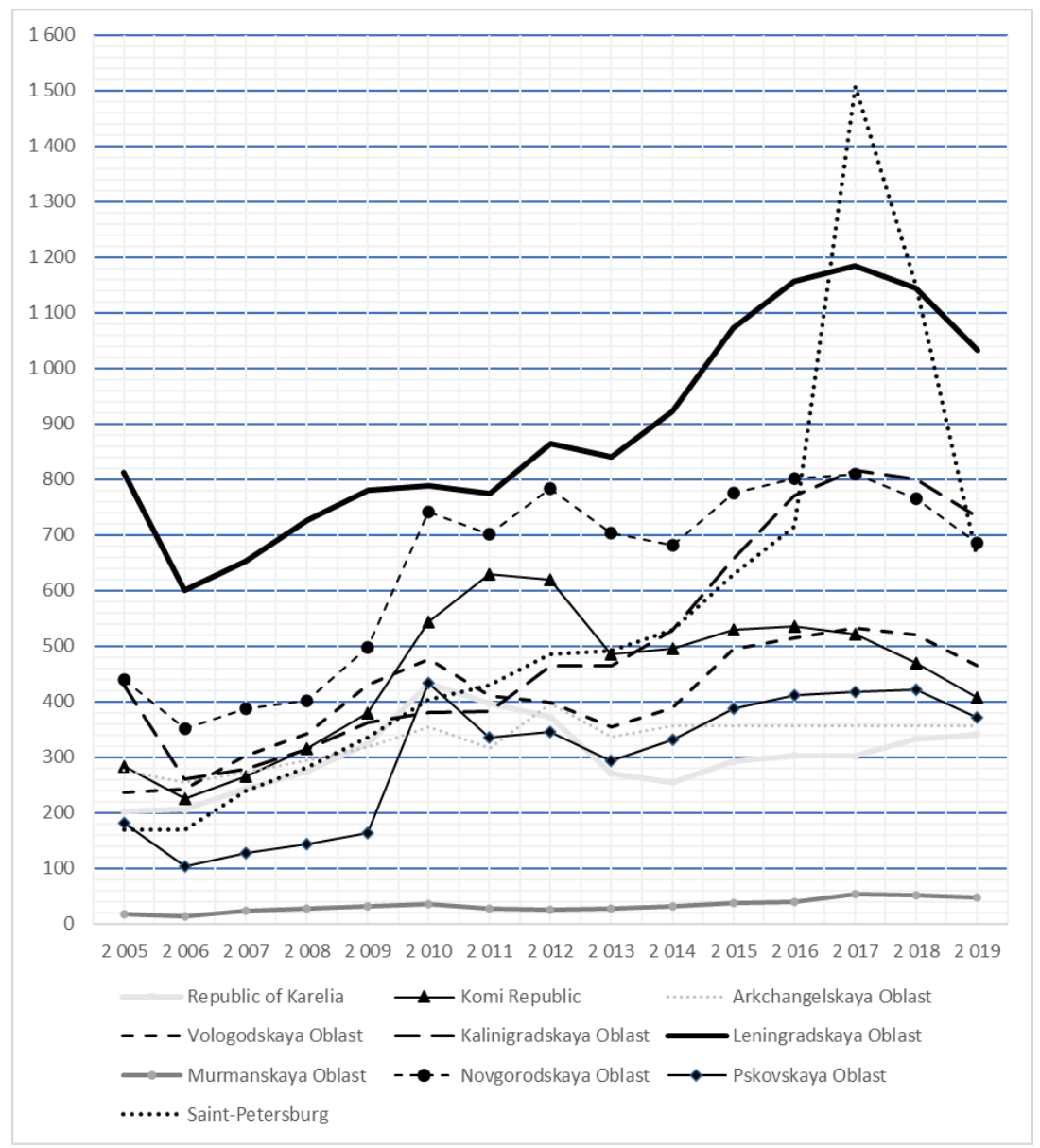

Fig. 1 Amount of farm households in the District of the North Western Federal District (source: elaborated by the authors).

To estimate the development of the farming it is more interesting to view the share of farm households of the whole population and of the rural population only. The Figure 2 shows the share of farm households of the North Western Federal District population. We see that the share of Novgorodskaya Oblast is the highest during the whole period. It is also should be mentioned that nevertheless the share of Novgorodskaya Oblast is the highest in the North Western Federal District, it makes less than $1 \%$, which is very little. Regarding Novgorodskaya Oblast, another point is that there is the lack of jobs in this District and the majority of population prefers to work in Saint-Petersburg which is very close to Novgorodskaya Oblast. 
We also see that the share of farm households of Kaliningradskaya Oblast rises more constantly nevertheless it faces several step down.

The share of Arkchangelskaya Oblast farm households is very small, but we also see that its share can be compared with the share of Vologodskaya Oblast farm households. The middle positions take the rest regions.

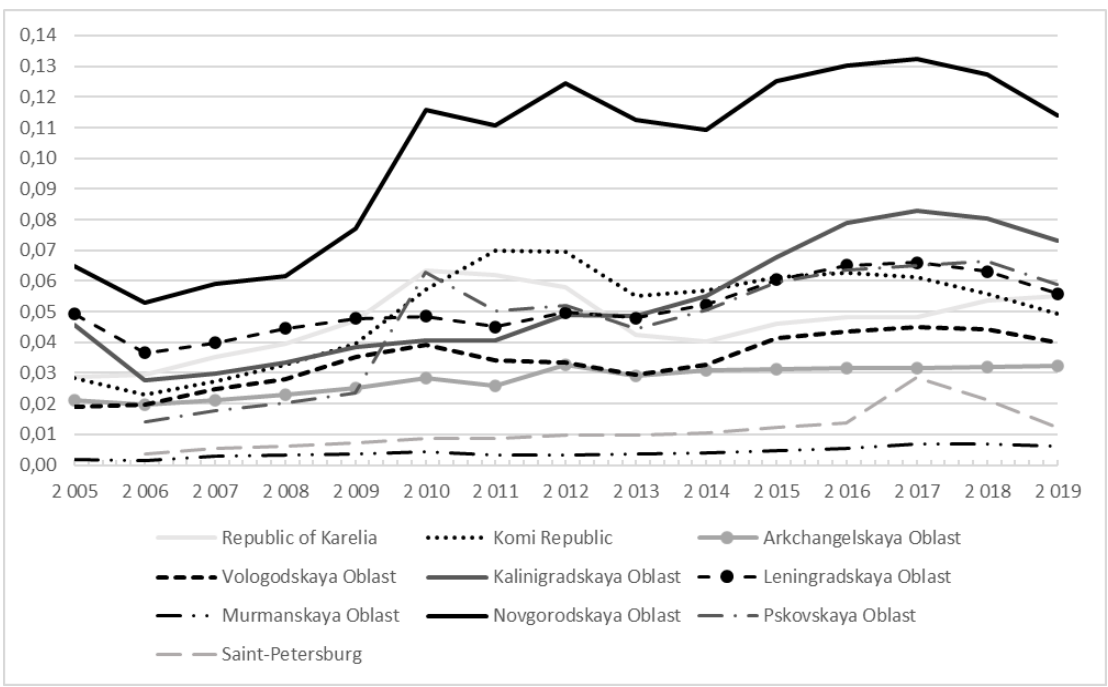

Fig. 2. Share of farm households of the whole North Western Federal District population, \%.

The third step is to analyze the farm houlseholds' share of the North Western Federal District rural population. It helps to understand real share of rural population involved into farm entrepreneurship. According to the Fig. 3, we see that the share of Novgorodskaya Oblast stays the highest. Then it is followed by Kaliningradskaya Oblast. Unfortunately, even the highest share does not exceed $1 \%$.

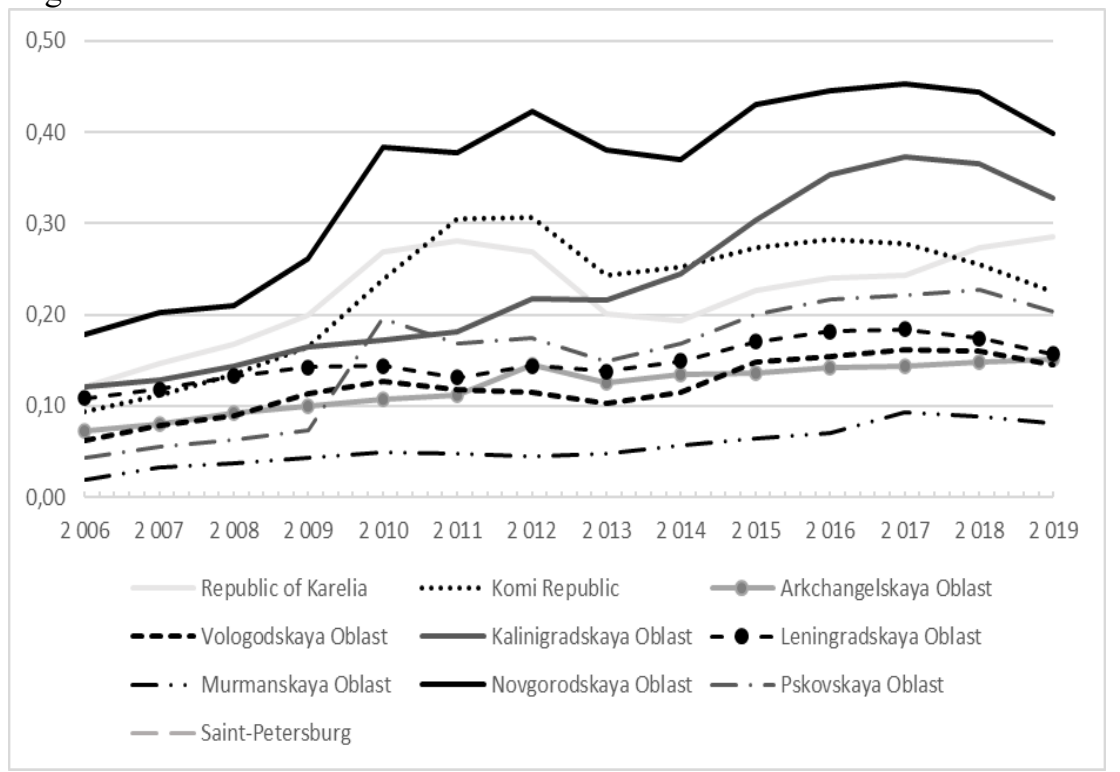

Fig 3. Share of farm households of the North Western Federal District rural population, \%. 


\section{Discussion}

We see that the share of farm households in all districts of the North Western Federal District is quiet less and does not exceed $1 \%$. Such a share of an entrepreneurship contribute just a little to budgets of a territory. That is why we can say that the amount of farm households need to rise. We also see the sinuous grow of both the farm households amount and its share. Nevertheless, there are declines the following rise surpasses the preceding decline. Small amount of farm households is seemed to make disappear threatens about environmental issues, as far as the need in investment in education of farmers. But we argue that the more educated locals are, the more they are involved into entrepreneurial activity, which is, in the countryside, very often connected with farming. The more entrepreneurs are on the territory, the more they are concerned about preserving their own of bottom up development takes place.

According to our field studies of social networks, at the present time rural individuals are more concerned about preserving their livelihood and preventing ecological deterioration. We can see how locals gather in small groups to find finances for ecological projects, to clean a territory. And the positive point is that local entrepreneurs usually help financially or by different types of resources. That is why we also see the important role of small farming development for sustainable development of a territory.

\section{Conclusion}

The research of the amount of farm households and the share of farm households shows that it rises gradually. We also see that the time of the national recession influences badly on the amount and share of farm households, the subsequent rise comes quite fast and exceeds the preceding index. As far as the contribution of agricultural products of the North Western Federal District is significant for Russia, we see the importance of farmers' support to stop and prevent poverty, as a result to protect the environment thanks to bottom up development, and to achieve sustainability. At the present time, according to our interviewing of rural locals, they are interested in entrepreneurship with the help of Internet but dot not aware of tools to do it. At the same time, we see that farming can use Internet tools to promote, sell products, to broaden network and for educational goals. So we assume that as far as the amount farm households and the share of farm households rise that farmers should also produce not material and importable products only, but find sorts of non-importables connected with their main production and sell and promote them via Internet. So they will be able to raise and diversify their incomes.

\section{References}

1. T. A. Masron, Y. Subramaniam, Does Poverty Cause Environmental Degradation? Evidence from Developing Countries, Journal of Poverty, 1-24, (2018) DOI: 10.1080/10875549.2018.1500969

2. N.A. Mironova, K.K. Kharlamova, O.A. Plastinina, Enterprises of Small Forms of Management Condition and Developing in the Vologda Region, Scientific Journal "Dairy Bulletin", 16 (4), 97-106, 2014

3. T.E., Marinichenko. Small Business Forms - Their State And Prospects of Development, Journal of VNIIMZH, 26 (2), 204-10, 2017

4. L. Christiaensen, L. Demery, J. Kuh. The Role of Agriculture in Poverty Reduction An Empirical Perspective (RePEc, 2006) DOI: 10.1596/1813-9450-4013 
5. C. Ray, Culture Economies: a perspective on local rural development in Europe, Centre for Rural Economy, Dept. of Agricultural Economies and Food Marketing, 2001

6. J.D. Van Der Ploeg, H. Renting, G. Brunori, K. Knickel, J. Mannion, T. Marsden, K. D. Roest, E. Sevilla-Guzmán, F. Ventura, Rural Development: From Practices and Policies towards Theory, Sociologia Ruralis, 40 (4), 391-408, 2000, DOI: 10.1111/1467-9523.00156

7. Samah, H. Azril Mohamed Shaffril, J. Lawrence D'Silva, M. Abu Hassan, Information communication technology, village development and security committee and village vision movement: A recipe for rural success in Malaysia, Asian Social Science, 4, 13644 (2010)

8. D.O. Strebkov, A.V. Shevchuk, M.O. Spirina, Self-Employment In The Remote Work Market: Diffusion In Innovative Labor Practice, The Monitoring, 6, 89-106 (2016) DOI: 10.14515/monitoring.2016.6.06.

9. C. Cunha, E. Kastenholz, M. J. Carneiro, Entrepreneurs in rural tourism: Do lifestyle motivations contribute to management practices that enhance sustainable entrepreneurial ecosystems?, Journal of Hospitality and Tourism Management, 44, 215-26 (2020)

10. M. Fedorova, I. Aleksandrov, A. Parshukov, E-commerce in Russian rural areas as a tool for regional development, E3S Web of Conferences. INTERAGROMASH, 175, 13046 (2020) DOI: 10.1051/e3sconf/202017513046

11. H. Kaila, F. Tarp, Can the Internet improve agricultural production? Evidence from Viet Nam, Agricultural Economics, 50, 675-91 (2019) DOI: 10.1111/agec.12517

A. Abdul-Rahaman, A. Abdulai, Social networks, rice value chain participation and market performance of smallholder farmers in Ghana?, African Development Review, 32(2), 216-27 (2020) DOI: 10.1111/1467-8268.12429

12. Abdul-Rahaman, A. Abdulai, Do farmer groups impact on farm yield and efficiency of smallholder farmers? Evidence from rice farmers in northern Ghana, Food Policy, 81, 95-105 (2018) DOI: 10.1016/j.foodpol.2018.10.007

13. M. Fedorova, I. Aleksandrov, Digital economy and green economy: rural unemployment and territorial self-development in Russia, E3S Web of Conferences 110, 02019 (2019) https://doi.org/10.1051/e3sconf/201911002019

14. J. R. Anderson, Environmental Issues and Farming in Developing Countries, (RePEc, 2002)

15. L. Yu. Piterskaya, N.A. Tlisheva, Y.N. Koshko, A. V. Piterskaya, Problems of Small Bussiness Development In Agricultural Industry, Scientific Journal of KubSAU, 133(9), 1-18 (2017) DOI: 10.21515/1990-4665-133-111

16. L. Pushkareva, M. Pushkarev Experience economy in the system of culture and education, E3S Web of Conferences 135, $04070 \quad$ (2019) DOI:10.1051/e3sconf/201913504070 